\title{
Mechanism of heat transfer for gas-liquid two-phase flow in deep drilling
}

Richeng Zhong ${ }^{1}$, Zhenbin Peng ${ }^{1}$, Haidong Jiang ${ }^{2 *}$

${ }^{1}$ School of Geoscience and Information Physics, Central South University, Changsha, Hunan, 410083, China

${ }^{2}$ Institute of Resources and Environmental Engineering, Guizhou University of Technology, Guiyang, 585003, China

Corresponding Author Email: 59366197@qq.com

https://doi.org/10.18280/ijht.360322

Received: 8 January 2018

Accepted: 10 June 2018

\section{Keywords:}

drilling fluid, density, rheology, heat transfer mechanism, gas-liquid twophase

\begin{abstract}
Drilling fluid cooling technology is one of the key techniques of drilling technology. In order to study the influence of mechanism of drilling fluid on temperature and pressure, especially on thermophysical parameters and rheological properties, as well as the heat transfer mechanism between bubbles and liquid flow inside and outside the liquid film by test, simulation and theoretical research. Firstly,

the test on thermophysical parameters of 10 kinds of drilling fluids at 7 different temperatures and 3 different pressure were analyzed, which would provide the key parameters for the establishment of downhole gas-liquid two-phase model. Then, study on rheology of cement slurry under high temperature and high pressure, and its heat transfer equations were derived. The results showed that the specific heat of mud decreases with the increase of density, and the thermal conductivity increases with the increase of density, almost linearly. Besides, gas is the main factor affecting heat transfer inside the well.
\end{abstract}

\section{INTRODUCTION}

Mud drilling fluid system has the characteristics of low solid content [1], good rheology, strong stabilizing ability, low damage and low cost, so it was widely used.

Drilling fluid temperature is too high, not only affect its performance, but also influence the ambient temperature of downhole drilling tools and guide testing tools, even influence wellbore stability, service life and drilling rate [12].

Drilling fluid is called the blood of drilling technology. With the development of geothermal resources, deep-sea drilling, deep mineral drilling and deep drilling, the performance of drilling fluid is becoming more and more important [2-4]. With the development of international continental scientific drilling project, the depth of deep continental scientific drilling in China is $13000 \mathrm{~m}$ in the future. The temperature gradient is calculated by $3.0^{\circ} \mathrm{C} / 100 \mathrm{~m}$, and the bottom hole temperature will reach $390^{\circ} \mathrm{C}$. Therefore, under high pressure and high temperature environment, the research of heat transfer mechanism of drilling fluid arises at the historic moment. As the most widely used drilling fluid system, it is very important to study the heat transfer mechanism of mud under high temperature and high pressure.

\section{STUDY ON THE THERMAL PROPERTIES OF MUD}

It is proved in theory and practice that the thermal physical parameters and temperature of mud are closely related to pressure, which seriously affect its rheological properties. Meanwhile, the parameters of thermal physical properties of mud are also one of the key parameters in the establishment of downhole circulation model [5], in which the thermal diffusivity is derived from thermal conductivity. Specific heat determines the specific heat and thermal conductivity of mud is the key parameter to determine its thermal diffusivity.

$\alpha=\lambda / \rho c$

In the formula: $\lambda$-thermal conductivity, unit $\mathrm{W} /(\mathrm{m} \mathrm{K}) ; \rho$ density, specific heat capacity per unit $\mathrm{Kg} / \mathrm{m}^{3}$; c-, unit $\mathrm{J} /(\mathrm{Kg}$ $\mathrm{K})$.

Table 1. Specific heat measurement data sheet for mud (20Mpa)

\begin{tabular}{ccccccccccc}
\hline type & \multicolumn{4}{c}{ polymeric slurry } & \multicolumn{4}{c}{ polysulfonated mud } \\
\hline temperature & 1.04 & 1.2 & 1.4 & 1.6 & 1.8 & 1.2 & 1.4 & 1.6 & 1.8 & 2.0 \\
$20 \sim 25^{\circ} \mathrm{C}$ & 3.6431 & 3.0837 & 2.9692 & 2.8347 & 2.5313 & 2.1457 & 3.0457 & 2.9532 & 2.5422 & 2.4776 \\
$30 \sim 35^{\circ} \mathrm{C}$ & 3.7985 & 3.1783 & 3.0276 & 2.9432 & 2.6031 & 3.3096 & 3.1679 & 3.0517 & 2.6388 & 2.5873 \\
$40 \sim 45^{\circ} \mathrm{C}$ & 3.9539 & 3.2729 & 3.0859 & 3.0478 & 2.6531 & 3.5981 & 3.4100 & 3.2121 & 2.6836 & 2.6379 \\
$50 \sim 55^{\circ} \mathrm{C}$ & 4.2258 & 3.3990 & 3.2026 & 3.1453 & 2.7032 & 3.8145 & 3.4369 & 3.3479 & 2.7956 & 2.7984 \\
$60 \sim 65^{\circ} \mathrm{C}$ & 4.4201 & 3.5567 & 3.3777 & 3.2466 & 2.8913 & 3.9948 & 3.4907 & 3.4348 & 2.9300 & 2.8992 \\
$70 \sim 75^{\circ} \mathrm{C}$ & 4.6532 & 3.7459 & 3.5527 & 3.4083 & 2.9517 & 4.2112 & 3.6491 & 3.5116 & 3.0420 & 3.0000 \\
$80 \sim 85^{\circ} \mathrm{C}$ & 4.9640 & 3.9667 & 3.7278 & 3.6741 & 3.1366 & 4.4997 & 3.8736 & 3.6231 & 3.2213 & 3.1210 \\
\hline
\end{tabular}


The specific heat and thermal conductivity of mud are restricted by the factors of temperature, density, composition and pressure. Therefore, considering the above factors, 10 kinds of mud of 2 types commonly used in deep oil drilling are prepared for laboratory test, in which the specific heat is determined by current calorimeter. The thermal conductivity of the slurry is measured by the linear heat source method in the unsteady heat flow method. The test results are shown in Table 1, 2.

Table 2. Data sheet for determination of thermal conductivity of Mud (20Mpa)

\begin{tabular}{ccccccccccc}
\hline mud type & \multicolumn{4}{c}{ polymeric slurry } & \multicolumn{4}{c}{ polysulfonated mud } \\
\hline Density $\left(\mathrm{g} / \mathrm{cm}^{3}\right)$ & 1.04 & 1.2 & 1.4 & 1.6 & 1.8 & 1.2 & 1.4 & 1.6 & 1.8 & 2.0 \\
Thermal conductivity $\left[\mathrm{W} /\left(\mathrm{m}^{\circ} \mathrm{C}\right)\right]$ & 0.514 & 0.58 & 0.676 & 0.787 & 0.932 & 0.533 & 0.616 & 0.723 & 0.87 & 0.955 \\
\hline
\end{tabular}

In order to further determine the heat transfer law of mud two-phase flow, it is necessary to study the variation of specific heat and thermal conductivity of mud gas and liquid with pressure. According to the test data provided by Shandong Shengli Oil Field Mud Company and logging Dr. Zhang Zhen, the borehole is $2000 \mathrm{~m}-3000 \mathrm{~m}$. The initial mud pressure is $12-16 \mathrm{MPA} \sim 6000-7000 \mathrm{~m}$, and the mud initial pressure is $18-21 \mathrm{MPa}$, However, due to the existence of bit pressure drop from injection pump force to borehole pressure during drilling, the results are as follows according to the bit pressure drop formula (formula 2):
$P_{b}=\frac{0.827 \rho Q^{2}}{C^{2} d e^{4}}$

In the formula: $\rho$ means density $\left(\mathrm{g} / \mathrm{cm}^{3}\right), \mathrm{Q}$ means bit mud displacement $\left(\mathrm{cm}^{3} / \mathrm{s}\right), \mathrm{C}$ means flow coefficient (0.95-0.985), de denotes nozzle equivalent diameter $(\mathrm{cm})$.

Because high-temperature and high-temperature mud is used in high-pressure and high-temperature drilling, the density of mud drilling fluid is $1.6 \mathrm{~g} / \mathrm{cm}^{3}$, and the pressure drop is about $10 \%$. The laboratory tests are carried out on 10 $\sim 20$ MPA, 40 80 temperature polymer mud and polysulfonated mud. The results are as follows:

Table 3. Specific heat measurement data sheet for mud $\left(1.6 \mathrm{~g} / \mathrm{cm}^{3}\right)$

\begin{tabular}{ccccccc}
\hline type & \multicolumn{5}{c}{ polymeric slurry } & \multicolumn{4}{c}{ polysulfonated mud } \\
\hline temperature & 10 & 15 & 20 & 10 & 15 & 20 \\
$20 \sim 30^{\circ} \mathrm{C}$ & 2.6425 & 2.833 & 2.8347 & 2.6748 & 2.8443 & 2.9532 \\
$30 \sim 40{ }^{\circ} \mathrm{C}$ & 2.7978 & 2.799 & 2.9432 & 2.9876 & 3.0082 & 3.0517 \\
$40 \sim 50^{\circ} \mathrm{C}$ & 2.9528 & 3.0029 & 3.0478 & 3.1969 & 3.2078 & 3.2121 \\
$50 \sim 60^{\circ} \mathrm{C}$ & 3.0246 & 3.0984 & 3.1453 & 3.3136 & 3.3358 & 3.3479 \\
$60 \sim 70{ }^{\circ} \mathrm{C}$ & 3.0420 & 3.1566 & 3.2466 & 3.3333 & 3.4174 & 3.4348 \\
$70 \sim 80^{\circ} \mathrm{C}$ & 3.2521 & 3.3456 & 3.4083 & 3.4608 & 3.4983 & 3.5116 \\
$80 \sim 85^{\circ} \mathrm{C}$ & 3.5963 & 3.6662 & 3.6741 & 3.4985 & 3.5727 & 3.6231 \\
\hline Note: unit of specific heat: $\mathrm{J} /\left(\mathrm{g}^{\circ} \mathrm{C}\right)$ & & & &
\end{tabular}

Table 4. Data sheet for determination of thermal conductivity of Mud $\left(1.6 \mathrm{~g} / \mathrm{cm}^{3}\right)$

\begin{tabular}{ccccccc}
\hline mud type & \multicolumn{3}{c}{ polymeric slurry } & \multicolumn{3}{c}{ polysulfonated mud } \\
\hline Density $\left(\mathrm{g} / \mathrm{cm}^{3}\right)$ & 10 & 15 & 20 & 10 & 20 & 20 \\
Thermal conductivity $\left[\mathrm{W} /\left(\mathrm{m}^{\circ} \mathrm{C}\right)\right]$ & 0.776 & 0.782 & 0.787 & 0.715 & 0.716 & 0.723 \\
\hline
\end{tabular}

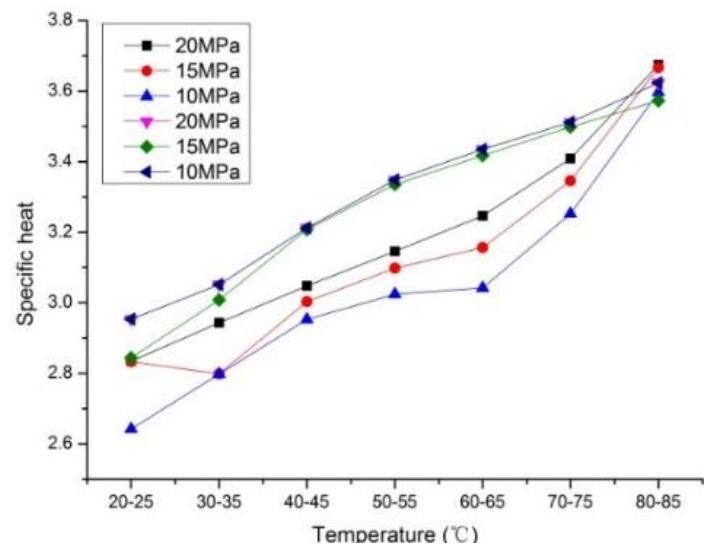

Figure 1. Specific heat-temperature-sensitive data analytical diagram

Therefore, the sensitivity factor analysis based on the test data, as shown in figure $1 \& 2$, shows that the specific heat of the mud is obviously much more strongly affected by the temperature than the pressure, and the slope of the specific heat pressure curve is gentler when compared with the straight-line slope. The slope of specific heat temperature sensitivity is about 2 times of that of specific heat pressure curve.

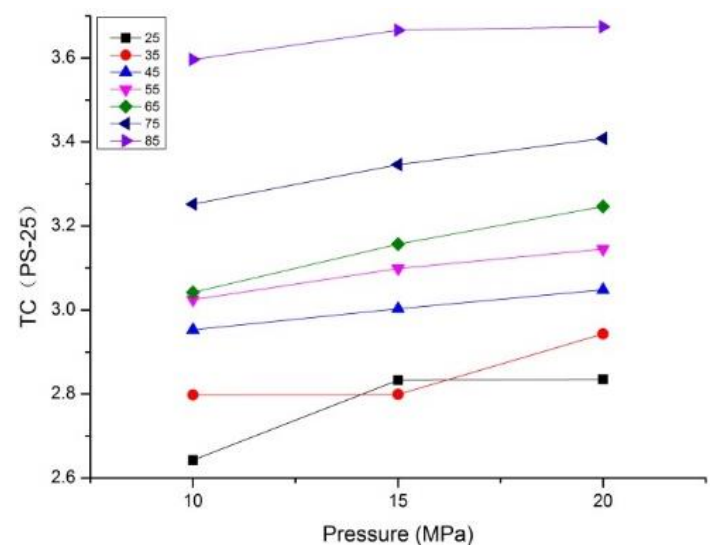

Figure 2. Specific heat pressure sensitivity data analysis 


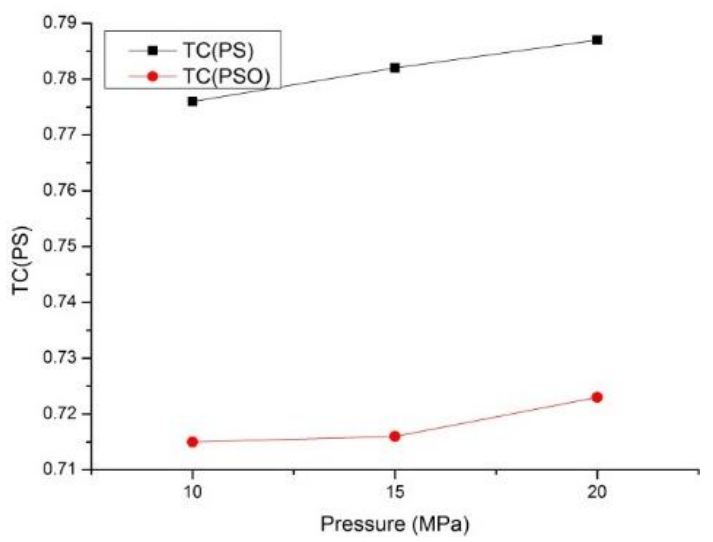

Figure 3. Thermal conductivity-pressure sensitivity data analysis

From Table 4 and figure 3, it can be seen that the influence of temperature and pressure on the thermal conductivity of mud is small, so the specific heat effect on mud under high temperature and high pressure is considered as the main thermal property index.

\section{SIMULATION TEST AND MODELING OF SLURRY RHEOLOGY UNDER HIGH TEMPERATURE AND HIGH PRESSURE}

Deep mud drilling fluid systems are highly dense, gelling, colloidal and suspending, and their rheological properties are extremely responsible [6]. The addition of various additives in deep drilling process not only deviates from Newtonian flow model, but also does not follow simple Muru model or H-B model [7-9]. Especially under the condition of high temperature and high pressure, the Brownian motion of mud becomes more intense, the molecules of admixture may have the function of resolution, decomposition and degradation, and the dispersity is better, and even the phenomenon of coalescence may occur.

Under the condition of high temperature and high-pressure mud rheology has Reynolds stress variation characteristic. Therefore, it is necessary to accurately master the spatial distribution characteristics of mud temperature pressure and concentration parameters in order to analyze the internal turbulence characteristics of mud rheology.

The traditional method of building mud rheological model in core drilling is turbulence pulsation analysis. The rheological parameters are estimated by analyzing the spatial distribution characteristics of the whole mud rheological field, face by side and point by point. For the deep well drilling process, the gas-liquid two-phase flow heat transfer mechanism occurs up and down the slurry level under high temperature and high-pressure conditions, because turbulent fluctuation analysis method can only describe a single fluid motion, unable to describe the gas - liquid two - state energy transfer mechanism, so it was necessary to build the model according Nonlinear Mechanism of Heat Transfer for gas liquid two - phase under high-temperature and high-pressure.

\subsection{Simulation experiment on rheology of high temperature and high-pressure mud}

In order to analyze the rheological properties of deep well mud under high temperature and high pressure, a simulation experiment was carried out on the mud provided by Shandong Shengli Oil Field Mud Company and Dr. Zhang Zhen, a mud logging company. The depth of the well is 6000 $\mathrm{m}$, the drilling pressure is $21 \mathrm{MPa}$ and the formation temperature is $250^{\circ} \mathrm{C}$. the experimental results of the simulation model were as follows:

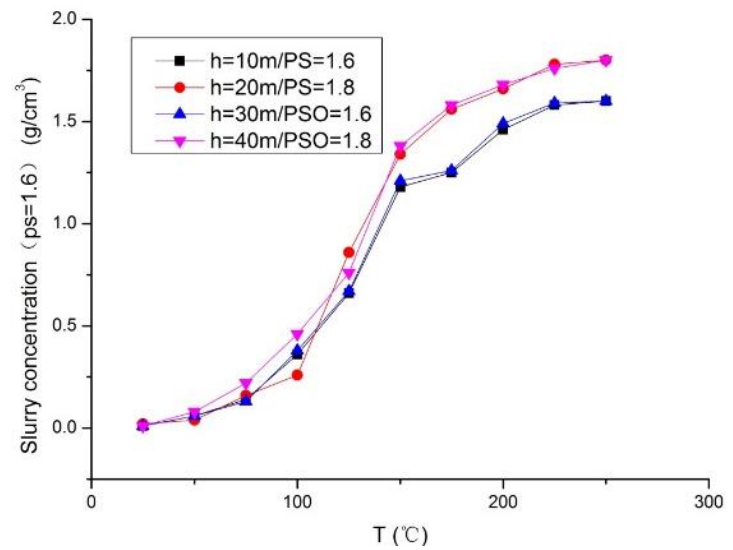

Figure 4. Density-temperature simulation experiment data chart

Experiments showed that the rheological characteristics of mud drilling fluid system show nonlinear distribution characteristics, and generally assume hyperbolic model.

\subsection{Rheology modeling of high temperature and high- pressure mud}

Many scholars have verified that the mud drilling fluid system is flowing from non-Newtonian fluid and its rheology is nonlinear (as shown in Fig. 4), so a nonlinear mathematical model is proposed to describe it. The rheological threeparameter initial shear stress $\tau_{x}$, consistency index $\mathrm{K}$ and flow pattern index $\mathrm{n}$ of the mud sampled earlier were tested by the laboratory experiment of high temperature and highpressure rheometer in the United States. The experimental results show that the mud is approximately hyperbolic in shape according to the plotting of the points. The model is assumed and the parameters are solved by the least square method. The solution results can be seen in the paper, Table 5 .

Table 5. Data sheet for rheological parameter determination of mud

\begin{tabular}{ccccccccccc}
\hline mud type & \multicolumn{4}{c}{ polymeric slurry } & \multicolumn{5}{c}{ polysulfonated mud } \\
\hline density $\left(\mathrm{g} / \mathrm{cm}^{3}\right)$ & 1.04 & 1.2 & 1.4 & 1.6 & 1.8 & 1.2 & 1.4 & 1.6 & 1.8 & 2.0 \\
\hline rheological parameters $\tau_{s}$ & 33.5 & 40.5 & 49.5 & 52.5 & 61.5 & 42.5 & 51.5 & 54.6 & 62.8 & 63.9 \\
\hline consistency index K & 0.288 & 0.846 & 1.46 & 3.48 & 7.81 & 1.28 & 2.86 & 3.66 & 7.96 & 8.32 \\
\hline flow pattern indexn & 0.04 & 0.08 & 0.14 & 0.36 & 0.72 & 0.15 & 0.25 & 0.40 & 0.76 & 0.88 \\
\hline $\begin{array}{c}\text { model fitting correlation } \\
\text { coefficient }\end{array}$ & 0.9691 & 0.9935 & 0.9762 & 0.9855 & 0.9877 & 0.9966 & 0.9924 & 0.9768 & 0.9994 & 0.98 \\
55
\end{tabular}


$\tau=\tau_{X}+\frac{K \gamma}{1+n \gamma}$

In the formula: $\tau_{X}$ is yield stress $(\mathrm{Pa}) ; \mathrm{K}$ is consistency coefficient ( $\mathrm{Pa} \mathrm{s}) \mathrm{n}$ is flow index (s); $\gamma$ is slurry shear rate (s$1)$.

The calculation results show that the hyperbolic model is the best model for describing the rheological characteristics of mud when the reliability is set $\alpha=0.05$.

\section{STUDY ON HEAT TRANSFER MECHANISM OF TWO-PHASE FLOW IN HIGH TEMPERATURE AND HIGH-PRESSURE DRILLING MUD}

In high-temperature and high-pressure drilling, gas-liquid two-phase flow exists widely and its heat transfer mechanism affects the temperature distribution on the drilling fluid surface [10-11]. At present, the research of drilling gas-liquid two-phase flow is mainly based on homogeneous phase model [14], split phase model or drift model. These models mainly consider the axial heat transfer mechanism of drilling fluid, [15] and rarely consider the radial heat transfer mechanism. Therefore, it is necessary to consider the heat transfer mechanism in different directions of different flow patterns of gas and liquid, so as to put forward the heat transfer mechanism of mud two-phase flow based on threedimensional direction.

The flow field diagram of high temperature and highpressure deep mud drilling fluid is simplified as follows:
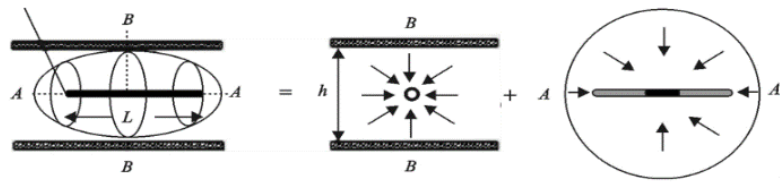

Figure 5. Three-dimensional flow field of core drilling in high temperature and High-pressure drilling

$\left\{\begin{array}{l}u_{t t}-\Delta u+|u|^{4} u=0 \\ \left(u, \partial_{t} u\right) /_{t=0}=\left(u_{0}, u_{1}\right) \in H_{x}^{s_{c}} \times H_{x}^{s_{c-1}}\end{array}\right.$

In the formula, $\Delta u$ is energy dissipation of mud in discharge region of cylinder, $u_{t t}$ is the pressure on the gasliquid two-phase interface in the $\mathrm{p}^{*} \mathrm{~m}$ region, $H_{x}^{S_{c}}$ is turbulent kinetic energy of three dimensional flow field of mud. Therefore, the radial flow equation of the liquid surface interface is as follows:

$$
q=\frac{q_{e}-p_{f}-\lambda\left(r_{e}-L / 4\right)}{\frac{10 u_{f f}}{k}\left(\frac{B}{5425.92 h}\right)^{n} \frac{1}{n-1}\left[r_{e}^{1-n}-\left(\frac{L}{4}\right)^{1-n}\right]}
$$

In the formula, $q_{e}$ is gas-liquid interface flow, $p_{f}$ is drilling fluid vertical pressure.

Assuming that the turbulent kinetic energy is $\mathrm{P}$, the mud will be subjected to the pressure of saturated bubble when $\mathrm{P}>\mathrm{P}_{0}$. According to the principle of turbulent flow in single medium and equilibrium of phase momentum, the three- dimensional rheological flow model of mud can be obtained as follows:

$$
\left\{\begin{array}{l}
v=\left|\frac{\partial p}{\partial r}\right| \leq \lambda \\
v=-\frac{k}{10^{3} u_{s}} \frac{\partial p}{\partial r}\left(1-\lambda / \frac{\partial p}{\partial r}\right)\left|\frac{\partial p}{\partial r}\right| \succ \lambda
\end{array}\right.
$$

In the formula, $v$ is mud rheological seepage velocity, $\mathrm{m} / \mathrm{s}$; $\mathrm{P}$ is the pressure of liquid level in drilling and $\mathrm{MPa} ; \mathrm{r}$ is the distance of horizontal drilling, $\mathrm{m} ; \lambda$ is medium transfer coefficient, $\mathrm{MPa} / \mathrm{m} ; \mathrm{K}$ is permeability, $\mu \mathrm{m}^{2} ; \mu \mathrm{s}$ is viscosity of 3D flow field, $\mathrm{mP} \cdot \mathrm{s}$;

Thus, the radial flow equation of the variable pressure distribution of the mud flow is formulated as follows:

$q=\frac{q_{e}-p_{w f}-\lambda\left(r_{e}-L / 4-\frac{\beta h}{2 \pi}+\frac{r_{w}}{2}(1+\beta)\right)}{\frac{10 u_{f f}}{\sqrt{k_{h} k_{v}}}\left(\frac{B}{5425.92 \beta h}\right)^{n} \frac{1}{n-1}\left[r_{e}^{1-n}-\left(\frac{L}{4}\right)^{1-n}+\left(\frac{\beta h}{L}\right)^{n}\left[\left(\frac{\beta h}{2 \pi}\right)^{1-n}-\frac{r_{w}}{2}(1+\beta)^{1-n}\right]\right]}$

In the formula, $\beta=\sqrt{k_{h} k_{v}}, k_{h}$ is mud horizontal permeability, $k_{v}$ is mud vertical permeability.

Therefore, by formula (7), the relationship between mud temperature, pressure and concentration distribution and rheology is obtained. However, under high temperature and high pressure saturation pressure, gaseous bubbly runs through the mud cycle, and there is turbulence between bubble flow and surrounding liquid flow, which results in slug flow. Due to the need to consider the bubble porosity and void distribution characteristics, The bubble physical state can be divided into Taylor bubble region, transition bubble zone and stable zone, while the saturated bubble with critical liquid level in drilling is the stable zone, so the fluid viscosity in the stable region is calculated by taking the value of liquid viscosity. At the liquid film interface, the heat exchange between the fluid and the bubble is balanced [16], thus establishing the following formula:

$\left(T_{f 2}-T_{f 1}\right) v_{f} H_{l f} \frac{\pi d_{1}^{2}}{4} p_{l} c=-q_{f} \pi d_{1} l d+q_{c} \pi d_{1} l d \sqrt{1-H_{l f}}$

In the formula, $T_{f 1}, T_{f 2}$ is temperature of slurry film outlet and inlet, $v_{f}$ is liquid film velocity, $q_{f}, q_{c}$ is respective the heat flow from the liquid film to the surrounding heat flow and from the bubble to the liquid flow, the partial differential solution of formula (8) is obtained.

$\frac{d T_{f}}{d l}=-\frac{q_{f}-q_{c} \sqrt{1-H_{l f}}}{4 v_{f} H_{l f} d_{1} p_{l} c_{p l}}$

In the formula, $T_{f}$ is the bubble temperature, $v_{f}$ is the bubble velocity, $\mathrm{p}_{1}$ is the liquid flow density, $c_{p l}$ is the liquid flow specific heat. The bubble thermal kinetic energy equation is:

$\frac{d T_{c}}{d l}=-\frac{q_{c} \sqrt{1-H_{l f}}}{4 v_{c}\left(1-H_{l f}\right) d_{1} p_{c} c_{p c}}$

In the formula, $T_{c}$ is the bubble temperature, $v_{c}$ is the 
bubble velocity, $\mathrm{p}_{\mathrm{c}}$ is the bubble density, $c_{p c}$ is the bubble specific heat. Due to the slow axial temperature transfer of bubbles and liquids in the wellbore, it can be considered that the axial temperature gradient is similar, and the simultaneous formula (9) (10) can be obtained:

$q_{c}=\frac{1}{(1+L) \sqrt{1-H_{l f}}} q_{f}$

Therefore, the temperature difference between the liquid film and the bubble is:

$T_{f}-T_{0}=\frac{(1+L) \mathrm{h}_{\mathrm{c}} \sqrt{1-H_{l f}}}{L U_{f}+(1+L) \mathrm{h}_{\mathrm{c}} \sqrt{1-H_{l f}}}\left(T_{c}-T_{0}\right)$

of which:

$L=\frac{v_{c}\left(1-H_{l f}\right) p_{c} c_{p c}}{v_{f} H_{l f} p_{l} c_{p l}}, q_{f}=u_{f}\left(T_{f}-T_{0}\right)$

$q_{c}=h_{c}\left[\left(T_{c}-T_{0}\right)-\left(T_{f}-T_{0}\right)\right]$

According to the overall heat flux, we can see that,

$\frac{1}{U_{f}}=\frac{1}{h_{f}}+\frac{d_{i}}{2 k_{p}} \ln \frac{d_{0}}{d_{i}}+\frac{d_{0}}{h_{0} d_{i}}$

The coefficient of convection heat transfer criterion of liquid film is:

$\operatorname{Re}_{f}=\frac{\rho_{f} u_{f} d_{f}}{\mu_{f}}, \mathrm{R} r_{f}=\frac{c_{p f} \mu_{f}}{k_{f}}$

The coefficient of heat transfer criterion between the gas core and the surrounding is:

$\operatorname{Re}_{c}=\frac{\rho_{f}\left(u_{c}-u_{f}\right) d_{f}}{\mu_{c}}, \mathrm{R} r_{c}=\frac{c_{p c} \mu_{c}}{k_{c}}$

In the formula, $c_{p f}, c_{p c}$ is respective specific the heat of liquid and gas phase; $k_{f}, k_{c}$ is respective the thermal conductivity of liquid and gas phases.

According to the formulas (15) and (16), the results of the two sections drilling $6000 \mathrm{~m}$, polymer mud density 1.6 , initial pressure $21 \mathrm{MPa}$ temperature 80 are as follows:

Table 6. Calculation results of heat transfer criterion coefficient for two-phase flow

\begin{tabular}{cccc}
\hline $\begin{array}{c}\text { phase } \\
\text { state }\end{array}$ & \multicolumn{3}{c}{ Heat transfer criterion coefficient } \\
\hline $\begin{array}{c}\text { liquid } \\
\text { state }\end{array}$ & specific heat & heat conductance & error rate \\
gas state & 1.3896 & 0.72 & $5.9 \% / 8.5 \%$ \\
\hline
\end{tabular}

Table 6 shows that the error between the calculated results and the experimental conclusions in Chapter 2 is less than $10 \%$, the confidence degree is between $\alpha=0.10$ and $\alpha=$ 0.05 , the reliability is high.

\section{CONCLUSION}

Through the laboratory rheological test, simulation test and theoretical calculation, the rheological and thermal properties of polymer mud drilling fluid system under high temperature and high pressure were studied, and the heat transfer mechanism of gas-liquid two-phase flow at high temperature and high pressure was put forward. The direct heat transfer equations of liquid film and bubble are derived under high temperature and high pressure. It also shows that under high temperature and high pressure, the thermal properties of liquid flow are almost twice as sensitive to temperature as those of pressure, while the thermal conductivity is less sensitive to pressure, and the bubble is more sensitive to temperature. However, the thermal conductivity has little sensitivity to the internal pressure of $20 \mathrm{MPa}$.

\section{ACKNOWLEDGEMENTS}

This research was funded by the special projects for promoting the development of big data of Guizhou Institute of Technology

\section{CONFLICT OF INTEREST}

The author confirms that this article content has no conflict of interest.

\section{REFERENCES}

[1] Van der Welle R. (1985). Void fraction, bubble velocity and bubble size in two phase flow. Int. J. Multiphase Flow 11: 317-345. https://doi.org/10.1016/03019322(85)90061-8

[2] Ghassan H. Abdul-Majeed AM, Mashat A. (2000). A mechanistic model for vertical and inclined two-phase slug flow. Journal of Petroleum Science and Engineering 27: 59-67. https://doi.org/10.1016/S09204105(00)00047-4

[3] Lucas GP, Mishra R, Panayotopoulos N. (2004). Power law approximations to gas volume fraction and velocity profiles in low void fraction vertical gas-liquid flows. Flow Measurement and Instrumentation 15: 271-283. https://doi.org/10.1016/j.flowmeasinst.2004.06.004

[4] Afshin J, Ghajar. (2004). Two-phase heat transfer in gas-liquid non-boiling pipe flows. 3rd International Conference on Heat Transfer, Fluid Mechanics and Thermodynamics, Cape Town, South Africa, pp. 21-24

[5] Guet S, Decarre S, Henriot V, Liné A. (2006). Void fraction in vertical gas-liquid slug flow: Influence of liquid slug content. Chemical Engineering Science 61: 7336-7350. https://doi.org/10.1016/j.ces.2006.08.029

[6] Zheng DH, Che DF. (2006). Experimental study on hydrodynamic characteristics of upward gas-liquid slug flow. International Journal of Multiphase Flow 32: 1191-1218. https://doi.org/10.1016/j.ijmultiphaseflow.2006.05.012

[7] Hazukua T, Takamasa T, Matsumoto Y. (2008). Experimental study on axial development of liquid film in vertical upward annular two-phase flow. International Journal of Multiphase Flow 34: 111-127. 
https://doi.org/10.1016/j.ijmultiphaseflow.2007.10.008

[8] Xu Y, Guan Z, Jin Y. (2017). Study of the ultrasonic propagation law in the gas-liquid two-phase flow of deepwater riser through numerical simulation. Journal of Petroleum Science \& Engineering 159.

[9] Dinaryanto O, Majid AI, Hudaya AZ. (2017). Experimental investigation on the initiation and flow development of gas-liquid slug two-phase flow in a horizontal pipe. Experimental Thermal \& Fluid Science 81:

93-108. https://doi.org/10.1016/j.expthermflusci.2016.10.013

[10] Zhu H, Duan J, Liu Q. (2018). Experimental study on oscillatory flow characteristics of gas-liquid two-phase flow. Heat Transfer Research.

[11] Lim YS. (2014). Heat transfer characteristics of gasliquid two-phase flow in microtubes. Thesis.

[12] Duan J, Liu H, Gong J. (2015). Heat transfer for fully developed stratified wavy gas-liquid two-phase flow in a circular cross-section receiver. Solar Energy 118: 338349. https://doi.org/10.1016/j.solener.2015.05.023
[13] Lim YS, Yu SCM. (2014). Numerical simulations of heat transfer characteristics of gas-liquid two phase flow in microtubes. International Journal of Thermal Sciences 86: 115-124.

[14] Lv J, Peng W, Bai M. (2015). Experimental visualization of gas-liquid two-phase flow during reciprocating motion. Applied Thermal Engineering 79: 63-73.

https://doi.org/10.1016/j.applthermaleng.2015.01.006

[15] Su Z, Liu J, Wang R, Chen E, Li X. (2018). Experimental study of novel reservoir protection agents for low permeability reservoirs in water-based drilling fluids. Chemical Engineering Transactions 66: 499-504. https://doi.org/10.3303/CET1866084

[16] Uddin MJ, Hoque AKMF. (2018). Convective heat transfer flow of nanofluid in an isosceles triangular shaped enclosure with an uneven bottom wall. Chemical Engineering Transactions 66: 403-408. https://doi.org/10.3303/CET1866068 